\title{
CHASSIS AJARDINADOS
}

Nara Beatriz Milioli Tutida

Universidade do Estado de Santa Catarina

\section{Resumo}

Este artigo descreve as experiências de produção de imagem poética em que está expresso um pensamento acerca da paisagem, mais especificamente o jardim, aqui concebido como ambiente privilegiado para a problematização da ação determinista que projetos de ocupação espacial concebidos a priori exercem sobre a paisagem. A decorrente modelização e padronização sofrida pelos espaços ajardinados é ressaltada por meio de operações poéticas que fraturam da superfície desse estilo de paisagem. Neste sentido, o foco recaí sobre a paisagem clichê respondendo ao problema dos processos culturais hegemônicos homogeneizantes, e, por conseqüência dos modos de constituição da subjetividade que essa paisagem forja, ao mesmo tempo em que é por ela forjada.

Palavras-chave

jardim, espaço liso, espaço estriado, paisagem clichê.

\begin{abstract}
This article describes the experiences of producing poetic image in which a thought is expressed about the landscape, more specifically the garden, here conceived as a privileged environment for the questioning of deterministic action that projects designed to advance space occupation have on the landscape. The resulting modeling and standardization suffered by garden areas is highlighted by a process that fracture surface poetic style of landscape. In this sense, the focus is on landscape cliché answer to the problem of cultural hegemonic homogenizing processes, and consequently the formation of modes of subjectivity forged this landscape, while it is wrought by it.
\end{abstract}

Keywords

garden, flat space, striated space, landscape cliché. 
Em minhas constantes deambulações por São Paulo observei, fotografando sistematicamente seus jardins, dois, entre tantos, dos modos de constituição de seus espaços e utilizo aqui para descrevê-los os conceitos de "espaço liso" e "espaço estriado", tal como postulado por Deleuze e Guattari (1997, p.189-190). O "liso" refere-se ao espaço sem bordas relativo ao crescimento espontâneo da vegetação nas praças, canteiros, calçadas, alguns jardins residenciais, etc. Em especial, reconheci esse estatuto também nas heras e trepadeiras que recobriam vários tipos de edificações, muros, cercas... Ao "estriado", correspondiam os jardins planejados, com seus passeios definidos, plantas geometricamente modeladas, tudo projetado de modo a ligar pontos, a traçar condutos.

Distinguindo as características próprias dos espaços "liso" e "estriado", Deleuze e Guattari apontam: para o primeiro, o mar - emblema da fluidez e plasticidade; e para o segundo, o formato cruciforme das "grelhas" - que caracterizam a planografia urbana. Temos, então, no modo de organização espacial "estriado", uma estratégia construtiva que parte do modelo, para dele extrair suas variações; enquanto que, no modo de composição espacial "liso", temos um agenciamento de forças imanentes, que começa em qualquer ponto, pelo meio, pondo o espaço em variação, numa espécie de "cromatismo generalizado" da paisagem.

Nesse sentido, por meio do "olhar do retorno" percebi em Florianópolis a paisagem filtrada pela polarização entre o "modo liso" e o "modo estriado": de um lado, aglomerados de edificações, e, nos interstícios, matagal - favela do Morro do Horácio -; de outro, as casas de jardins geometricamente cultivados - bairro de Jurerê Internacional -, cujas construções à beira-mar reproduzem em escala residencial, diversas estilizações palacianas, e também observei os econômicos conjuntos habitacionais populares implantados, planejadamente, na periferia.

Observando assiduamente o Morro do Horácio desde a janela do meu apartamento acompanhei o ritmo irregular do seu crescimento morfológico e a constante reconfiguração dos espaços e fluxos, barracos, vielas, becos, vegetação... Também freqüentei cotidianamente bairros populares e de elite que nasceram planejados. 


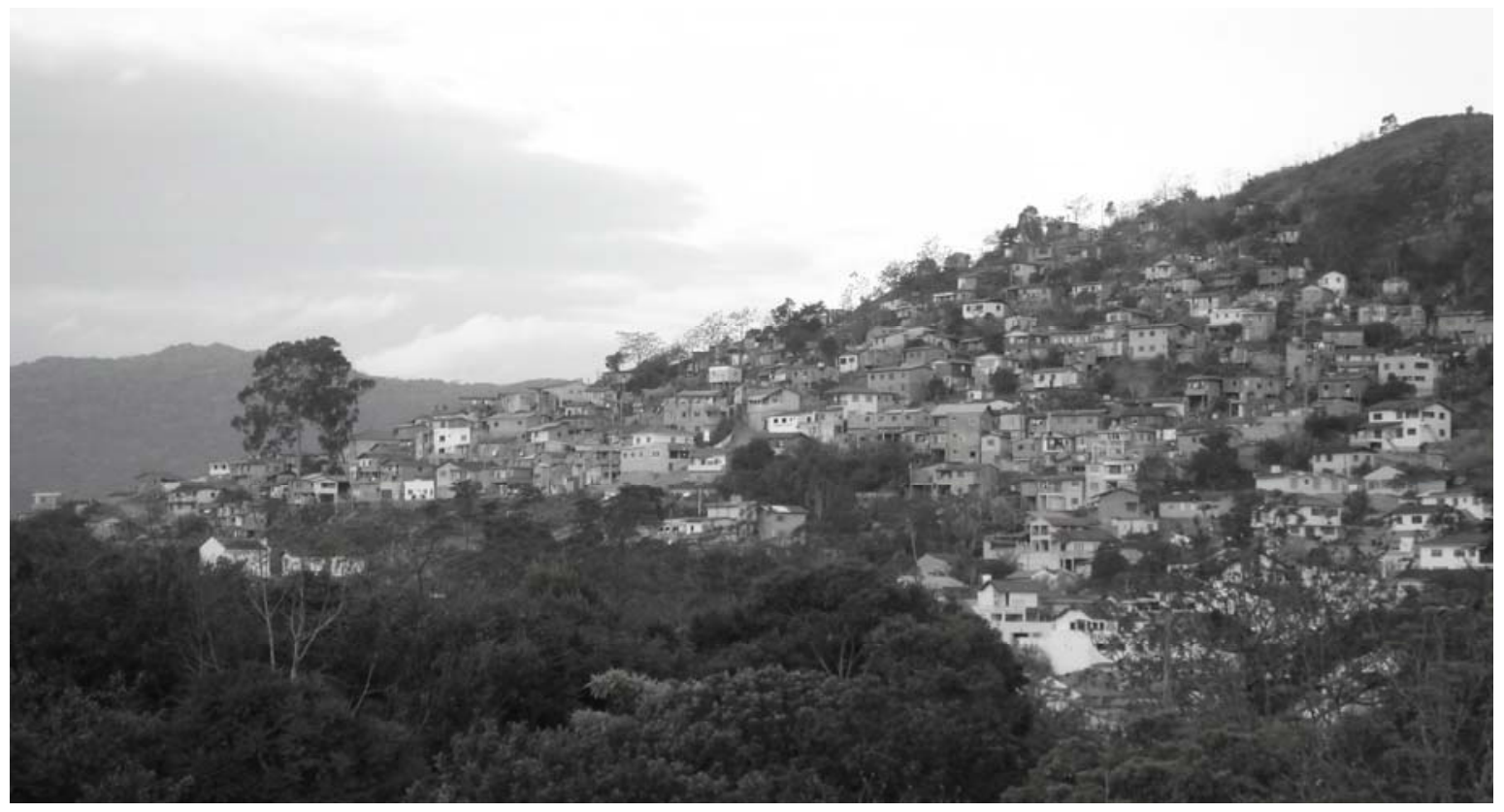

Morro do Horácio 2005

Ao contrapor o projeto urbanístico de Jurerê Internacional, juntamente com os projetos dos conjuntos habitacionais populares, à ocupação não planejada e desordenada do Morro do Horácio, uma questão se interpôs: qual a relação dos fluxos e dos bloqueios na constituição de um constructo paisagístico, e, por conseguinte, quais planos de existência determinam um ou outro modo de compor a paisagem? Daí deriva o problema do clichê e da "sociedade de imagens". A essa questão só poderia responder por meio de uma pesquisa da sensação, de modo empírico.

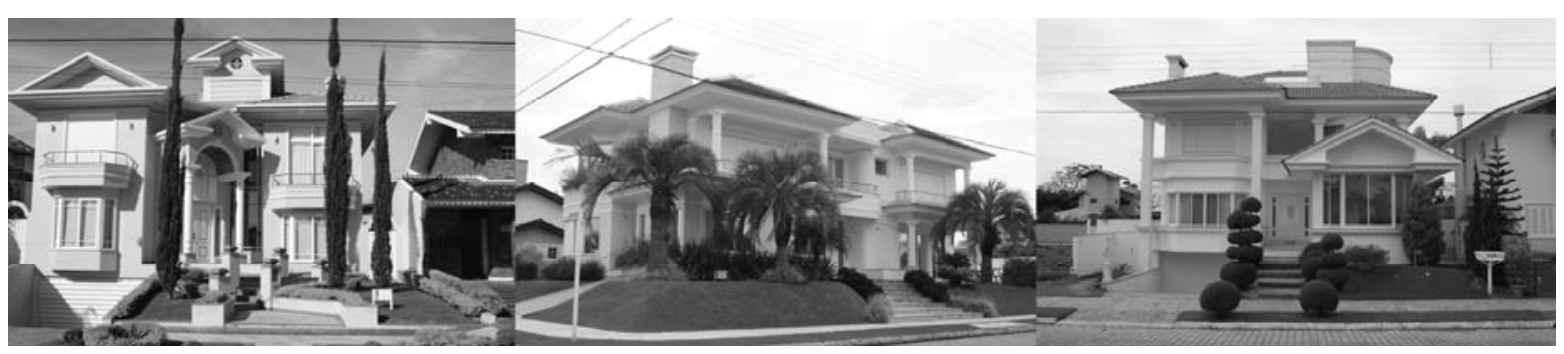

série de imagens (fotografias) de Jurerê Internacional 2007

Compreendi o fluxo por seu funcionamento, na medida em que algo passava e algo estava sendo bloqueado, e do mesmo jeito, algo o bloqueava ou o fazia passar. Então, os caminhos nos jardins e as ruas ou vielas no traçado urbano, eram lugares de passagem, elementos de ligação, condutos que faziam o trânsito de um ponto a 
outro, enquanto às suas margens estavam situados os pontos de paradas, que consistiam nas moradias ou noutros estabelecimentos, tanto de desaceleração quanto de suspensão total do movimento, assim também os cruzamentos, os faróis, os becos, etc.

Tratava-se de experimentar a paisagem em sua multiplicidade característica, seja nos planos de captura ou de fuga, em suas potências espaciais constitutivas. O que pode um corpo inserido numa paisagem, cuja composição implica apenas linhas de fuga, desestratificação de toda a natureza; ou o que pode um corpo num espaço composto para a captura?

Em cada caso trata-se de, primeiro, misturar-se ao fluxo, desterritorializar-se, dessubjetivar-se, liberar-se de um tempo medido e espacializado, tornar-se transporte de afetos e devires, empreender a fantasia, o delírio de percorrer terras distantes para criar nelas mundos possíveis; segundo, desacelerar, relação ao modo de constituição do ser? O estado conjurando o nomadismo; a sociabilidade subjugando a mundanidade, os bandos; a arborescência constrangendo o rizomático. A partir daí, aprofundei a pesquisa, selecionando na paisagem um lugar em que pudesse experimentar simultaneamente a maior variedade de espaços e suas relações constitutivas.

Foucault aponta os "sítios" do jardim paisagístico como o mais antigo tipo de heterotopia, já que o jardim consegue sobrepor num mesmo espaço real, à maneira de um palimpsesto, vários outros espaços, "sítios" até mesmo incompatíveis entre si. O jardim tornou-se, nesse contexto, um "fabuloso" objeto de estudo, uma maquete do microcosmo. Com efeito, o jardim é, ao mesmo tempo, a menor parcela e a totalidade do mundo: "heterotopia feliz e universalizante desde os princípios da Antiguidade".

O que faz um cipreste* na praia em Florianópolis?

\footnotetext{
* (árvore de até $45 \mathrm{~m}$ - Cupressus sempervirens -, da fam. das cupressáceas, com copa geralmente muito estreita e esguia, ramificações terminais lineares, de um verde forte, e com pequenos estróbilos globosos e pêndulos; nativa do Sul da Europa e do Sudoeste da Ásia, simboliza a tristeza; sua madeira, homogênea e aromática, foi usada em sarcófagos egípcios, móveis gregos, arcas medievais).
} 


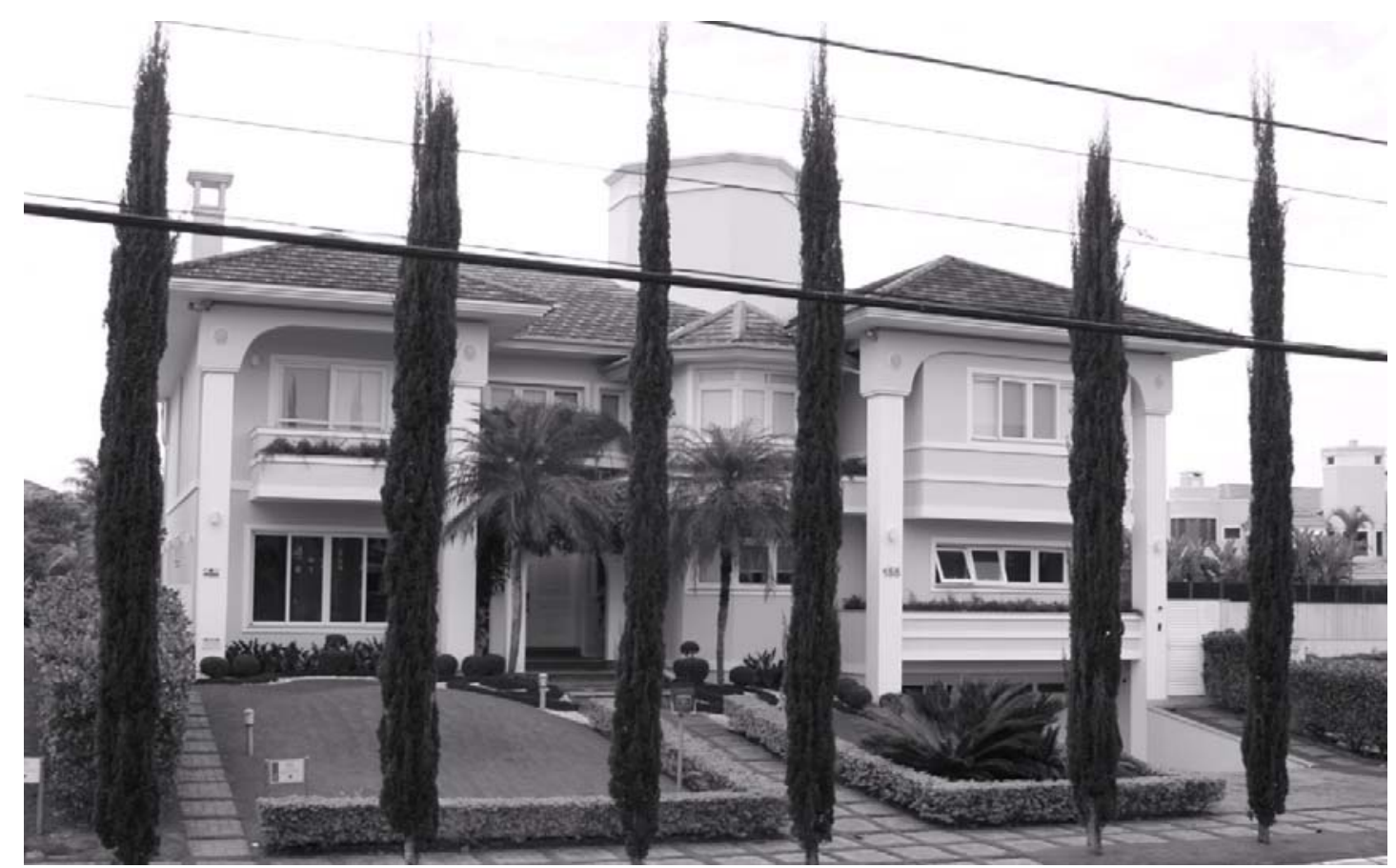

Jurerê Internacional (fotografia) 2007

Durante a realização da pesquisa de campo registrava fotograficamente imagens de jardim com variados pontos de vista: pequenos espaços situados no entorno de edificações de todo tipo; plantas diversas revestindo estabelecimentos, formando "jardins verticais"; varandas, alpendres e sacadas de prédios; vestíbulos, átrios, quintais, entradas de residências ou imóveis construídos para qualquer finalidade; estruturas recobertas por plantas como pergolatos e portais; praças, canteiros de ruas, avenidas. Também juntava imagens selecionadas em revistas de jardinagem, buscava na internet retratos dos jardins palacianos europeus, a fim de compará-los ao meu estoque de imagem realizado em campo.

Nas "viagens" aos jardins, tanto aos reais, quanto aos da internet ou das revistas e livros impressos, experimentava às vezes sensações de furor contra a medida, leveza contra a gravidade; vivenciava a intuição de um segredo em franca oposição à explicitude de uma forma racionalizada; sentia a vibração de uma potência contra a soberania do cânone; percebia a insurgência de uma máquina vital contra o aparelho ideológigo. Via o distribuir-se num campo aberto, o ocupar o espaço, preservando a possibilidade de surgir em qualquer ponto; o movimento já não era ir de um ponto a outro, mas tornar-se perpétuo, sem alvo nem destino, sem partida nem chegada - espaço "liso". Parecia haver uma conexão do conteúdo e da expressão por si mesmos. 
Como colocar a questão? Lutar contra o clichê, existindo dentro desse mesmo dispositivo, e subvertê-lo? É em termos de concorrência, num campo de interação, que é preciso rivalizar com ele; pensar a exterioridade e a interioridade, as máquinas de metamorfose e os aparelhos identitários, os bandos nômades e os estados civilizados. Um mesmo espaço circunscreve sua interioridade em estados, mas descreve sua exterioridade naquilo que escapa aos estados ou se volta contra eles.

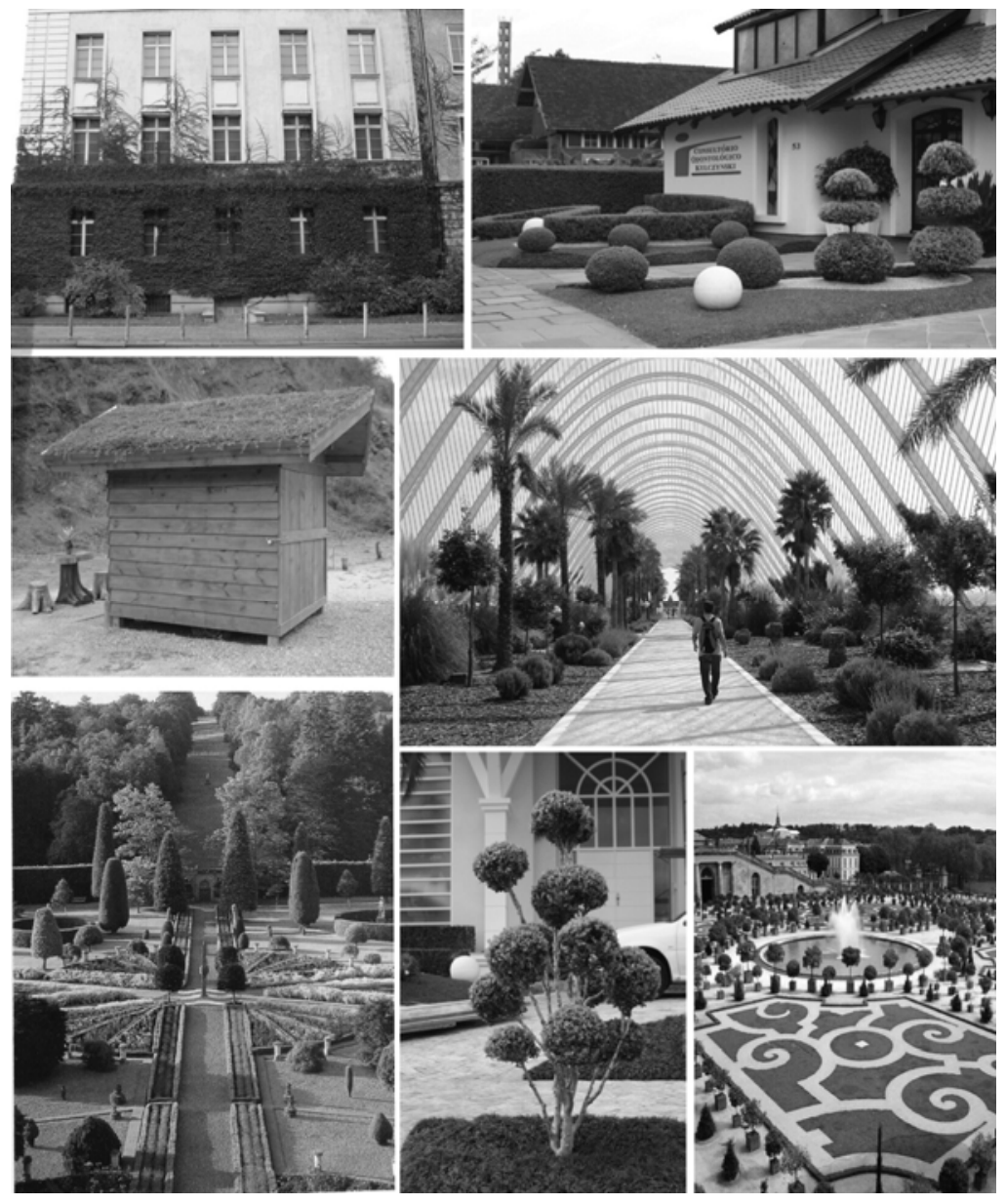

série de imagens de jardins (fotografias e recortes de revistas)

A paisagem do "sítio" do jardim francês é tipicamente estratigráfica, sendo constituída por "agenciamentos" ocorridos no apogeu do Império Romano. Dentre esses "agenciamentos", o destaque é dado aos postulados do livro De Architetura, célebre tratado de Vitrúvio, escrito em 27 a.C. e considerado o único texto datado da Antiguidade clássica que chegou até nossos tempos. Segundo Justino Maciel (2007, p. 44) a arquitetura vitruviana constituia-se de: "ordenação" (ordinatio), "disposição" (dispositio), "euritmia" (eurythmia), "comensurabilidade" (symetria), "conveniência" (decor) e "distribuição" (distributio). 
A "disposição", relativa ao modo gráfico de apresentação das obras arquitetônicas, subdividia-se em: "planta" (ichnografia), "alçado" (orthographia) e representação "cenográfica", em perspectiva (scaenographia). A "euritmia" dizia respeito à correspondência equilibrada entre a altura, a largura e o comprimento, ou seja, às diferentes dimensões de uma edificação. A "comensurabilidade" se referia à relação harmoniosa, regular e simétrica entre o todo e as partes. A "conveniência" ou decoro, dispunha da organização dos ornamentos no espaço arquitetônico, com relação à sua adequação às normas culturais e convenções artísticas, bem como sua pertinência em definir não só a circulação pelos espaços, mas também conferir distinção e atribuir valores aos variados comportamentos sociais. A "distribuição" se referia tanto à gestão, à administração do espaço em termos pragmáticos, ou seja, em relação ao equilíbrio entre orçamento e disponibilidade de materiais.

No De Pintura, Alberti retoma os temas da arquitetura vitruviana, em especial a representação cenográfica tal como definida no De Architetura, contudo substituindo a escrita descritiva e pragmática de Vitrúvio pela demonstração matemática das leis da perspectiva. Essa sistematização do dispositivo da perspectiva permitiu a criação de uma ilusão de espaço tridimensional sobre um plano bidimensional. Não obstante os séculos que separam De Architetura e De Pintura, tanto em Vitruvio, que viveu no apogeu imperial da pax romana, quanto em Alberti, já num contexto renascentista, o dispositivo da perspectiva tende sempre a uma estase do espaço e do tempo, estase que representa um impedimento do devir.

Esse impedimento secular do devir se estende à planografia do jardim paisagístico francês do século XVII, na forma de uma versão estereotipada dos cânones e valores da cultura greco-romana e renascentista - ou seja, é uma paisagem estratigráfica de signos, cujo plano de organização é análogo a um palimpsesto de clichês.

Escolhi o jardim francês como emblemático do clichê paisagístico. Trabalhei sobre suas imagens realizando operações de corte, contração, deslocamentos, no sentido de provocar um abalo no significado cultural paisagístico ali cristalizado. Procurei com esses trabalhos, tratar o problema dos processos culturais hegemônicos homogeneizantes. Consequentemente, este problema remete aos modos de constituição de uma subjetividade que se submete a supremacia de culturas que 
se supõem superiores, mas que não conseguem senão reproduzir continuamente o mesmo sistema ou conjunto de juízos que elaborou, supondo tratar-se de uma verdade óbvia ou evidência natural.

De modo a orientar meus procedimentos poéticos não só na fase de seleção das fotografias, mas, sobretudo na construção dos trabalhos, estudei a distinção que Roland Barthes ${ }^{1}$ faz entre os termos "studium"- referente aos aspectos simbólicos e sensológicos de uma fotografia - e "punctum" - referente ao "sentir", que se dá ao atentarmos para o detalhe pungente e a leitura temporal da foto como "isso foi".

Especificamente no caso dos trabalhos aqui apresentados, o studium se refere a todos os aspectos culturais do "sítio" jardim - a idéia de espaço "modelizado", "geométrico", "racionalista", bem como a idéia de "caminho" e "passagem" considerando que tais elementos do jardim são simbólicos, culturais e como tal, a paisagem aí não é um efeito de fabulação, mas recognição e evocação dos jardins. Em resumo: arquitetura verde, passagens, portais, todos esses elementos estão previamente codificados, todos nós sabemos o sentido desses elementos, eles não causam estranheza nem nos desorientam. Até mesmo a dimensão cenográfica do jardim é um modelo a priori - seja ele um jardim francês ou inglês, tudo já está codificado. O jardim é o elemento studium das fotografias impressas sobre chassis de mdf, pois tudo aquilo que pude nomear e descrever em seu traçado não pode mais me ferir.

Diferentemente, remeto ao punctum, os recortes efetuados nas fotografias espessadas pelo mdf, pois, é justamente nessas cavidades que se forja um devir cujo efeito é o distúrbio na imagem. Em cada caminho vazado nos "chassis ajardinados", há um estremecimento que desorienta, justamente porque não é mais possível defini-lo, não conclusivamente - por isso mesmo é um punctum: o detalhe, a barreira, a fenda e o vazado que não se pode nomear, fere.

Etimologicamente, a perspectiva linear significa "visão clara". Isso quer dizer que os objetos representados numa superfície plana são vistos sem referência a suas

\footnotetext{
${ }^{1}$ Em A Câmara Clara, Roland Barthes distingue a coexistência de dois elementos heterogêneos "punctum" e "studium": O studium é a porção simbólica sensológica da fotografia, ou seja, é a sua estrutura como código; é o punctum, que remete ao sentir, devir sensível de uma paisagem. É pelo punctum que olho a fotografia de uma paisagem e estremeço: a paisagem já esteve ali, porém já não está mais; e, no entanto, ao meu olhar, ela continua ali. Na fotografia a paisagem é a imagem viva de uma paisagem morta.
} 
formas ou relações absolutas. Na expressão artística do dispositivo perspéctico, o desenho do quadro é calculado de modo que seja válido para um único ponto de vista. (GIDEON, 2004, p. 58)

Dentre os elementos codificados no palimpsesto de clichês paisagísticos, é via de regra que a "vista clara" do dispositivo da perspectiva é uma noção que não se costuma contestar: se aceita a naturalização de um dispositivo visual predominante datado - pictórico em sua gênese -, como modelização compositiva intrínseca ao quadro fotográfico.

Assim, uma questão central se torna premente: se o "sítio" jardim é, em si mesmo, palimpsesto de clichês, conclui-se que na atualidade o dispositivo-jardim equivale a um clichê-dispositivo. Já não se trata aqui de abordar linhas de fuga, mas entrelinhas de fuga na articulação entre dispositivo-jardim e clichê-dispositivo, já que aquilo que vemos na atualidade é o acúmulo de dispositivos sobre dispositivos sobre dispositivos, de clichês sobre clichês sobre clichês. Daí atinarmos com uma questão crucial nesta pesquisa: o dispositivo jardim e suas linhas de fuga seriam eles mesmos clichês?

Pensando dessa maneira, se via de regra as máquinas de visão reciclam modelos da realidade sensológica, via de fuga, elas desnaturalizam visões do mundo e, ao mesmo tempo, criam uma nova imagem, visão de mundo.

Nesse contexto, como abrir uma linha de fuga no dispositivo da perspectiva renascentista - ele mesmo uma máquina de visão secular, portanto já da ordem do sensológico? De início podem-se adotar estratégias que ponham em devir dispositivos e linhas de fugas, mas isso só não basta. Existiria no dispositivo jardim, além de linhas de fuga e entrelinhas fugazes equivalentes a limiares de passagem entre o dispositivo da perspectiva, que nos faz ver paisagens que estão deixando de ser as nossas, um outro dispositivo, o fotográfico, que nos faz vislumbrar paisagens por vir, por habitar? Assim, no caso desta pesquisa, é importante ressaltar tais entrelinhas, como demarcações da passagem do paradigma pictórico para o fotográfico. 
câmera obscura. Digo: não, são os químicos. Pois o noema "Isso foi!" só foi possível a partir do dia em que uma circunstância científica (a descoberta da sensibilidade dos sais de prata à luz) permitiu captar e imprimir diretamente os raios luminosos emitidos por um objeto diversamente iluminado. A foto é, literalmente a emanação de um referente. De um corpo real, que estava lá, partiram radiações que vêm me atingir, a mim, que estou aqui [...]." (BARTHES, 1984, p.121)

Aproximando o "conceito de sensologia" de Mario Perniola ao texto de Roland Barthes, pode-se dizer que, a partir do momento em que o "já-sentido" (o studium, nos termos de Barthes) é subsumido pelo "sentir" (o punctum) até ser recalcado, o sujeito da experiência (o que olha) é lançado numa linha de fuga, se dissolve experimentando a pura exterioridade. Com os trabalhos a correlação fica assim: "jásentido", studium, fotografia, e, "sentir", punctum, recorte. Após transpor o portal (tela verde), habitar a fenda (vazio branco) se é arremessado à parede, reterritorializado, mas em outra paisagem, à "terceira margem" da fenda - o "espaço liso".

Quando a paisagem já se encontra codificada, quando suas edificações e jardins cultivados obedecem a modelizações, sejam de que ordem forem - políticas, históricas, culturais, econômicas - estamos lidando com a indiferença sensológica, privados de encontros, de acontecimentos que poderiam desencadear devires sensíveis no corpo humano e no da paisagem. 


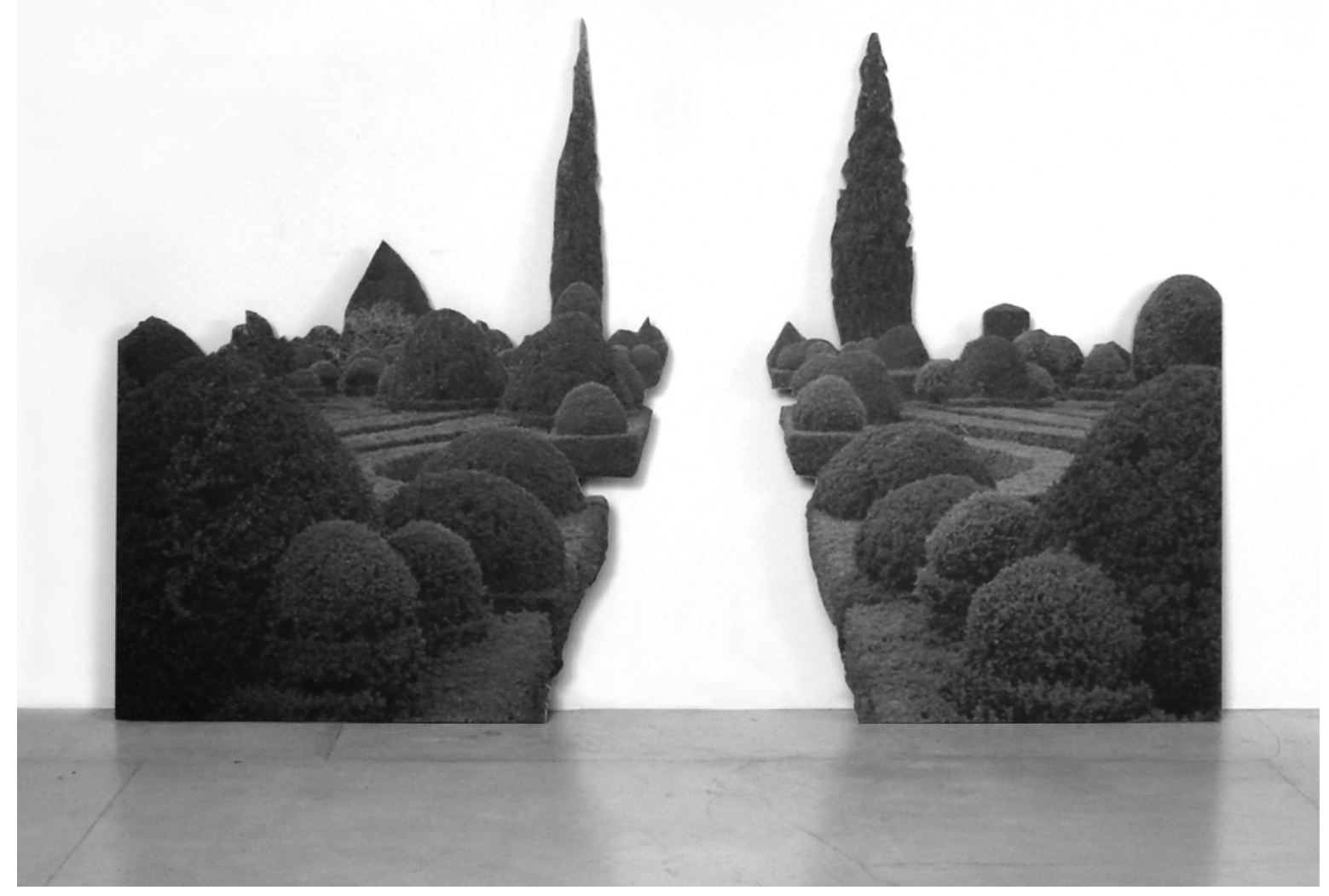

Ciprestes impressão em MDF 251 x $180 \times 0,3 \mathrm{~cm} 2007$

Os "chassis ajardinados" apresentam-se como portais, como indícios liminares que atestam que toda imagem "é estruturada como um limiar" (HUBERMAN, 1998, p. 243), pois nessa cisão inelutável entre a paisagem que meu "olhar do retorno" fabula e a paisagem sensológica da qual me tornei consciente, torno-me um corpo em constante trânsito, circulando por portais ajardinados e arrastando comigo os devires sensíveis, num movimento em que sinto o que fabulo e fabulo o que me sinto sendo. Com efeito, em seu conjunto, os "chassis ajardinados" são tomados em seu estatuto de processualidade criativa, ou seja, na perspectiva de seu "ser do sensível". Desse ponto de vista, são dispositivos capazes de cercar as imagens sensológicas, dandoIhes a sobrevida no devir sensível:

"As figuras estéticas (e o estilo que as cria) não têm nada a ver com a retórica. São sensações: perceptos e afectos, paisagens e rostos, visões e devires. [...] O devir sensível é o ato pelo qual algo ou alguém não pára de devir outro (continuando a ser o que é) [...]." (DELEUZE; GUATTARI, 1992, p. 229). 
Podemos ser insensíveis às imagens, quando ainda não a percebemos; podemos ser sensíveis em relação a uma imagem, se ela nos afeta; e, por último, podemos ser indiferentes a uma imagem, quando ela já se tornou clichê, paisagem sensológica. Segundo Bergson (1990), algumas imagens podem ser sem serem percebidas. Como tal, nosso corpo é insensível a elas, já que não são objetos de nossa recognição ou evocação: é como um ponto cego no campo de visão.

Diante das fotografias de jardim que compõem meu arquivo ou que foram utilizadas na realização dos trabalhos poéticos, posso dizer "isso foi" (Barthes), pois essas fotos atestam que os jardins estiveram ali, não importa por quanto tempo, diante do fotógrafo. Portanto, sejam essas fotografias da ordem do "sentir" ou, ao contrário, "sensológicas", elas representam o jardim enquanto um acontecimento no mundo. Entretanto, quando essas mesmas fotografias são impressas em mdf, elas continuam a ser imagens de jardim aplicadas sobre um chassi espesso recortado. Ou seja: "esse jardim pôde ser visto", já que é, também, um dispositivo espacial já sedimentado simbolicamente, uma visão recortada do nosso mundo.

Diferentemente, como objeto poético, os "chassis ajardinados" funcionam como linhas de fuga do dispositivo. Assim, nos embreamos por lugares fora do mapa, como se a visão do mundo e a visão de um mundo fossem traçados de um só caminho que não nos é dado de antemão, e que, portanto, para que seja percorrido, é preciso que seja criado.

É certo que todo dispositivo tem suas linhas de fuga - em direção às imagens que são sem serem percebidas. No caso do objeto poético, culturalmente ele pode ser visto e "isso foi". Mas, além disso, ele é poético e como tal pode criar um novo ponto de vista, pode criar um novo regime de imagens onde antes só havia um ponto cego - pode ser visto e "agora". Contudo, para que um novo regime de imagens exista ele também precisa ser criado; e dentre todas as infinitas imagens que são sem serem percebidas selecionamos apenas as adequadas à criação de um novo ponto de vista sobre a nossa civilização do clichê.

Se todo regime de imagens é um dispositivo, a tomada de consciência dos clichês faz com que a máquina de visão que Ihe dá sustentação possa finalmente ser vista. $E$ mais ainda: um objeto poético nos faz ver as imagens que eram sem serem percebidas, em suas entrelinhas de fuga. Assim, temos a co-presença entre a 
imagem e a visão do mundo conhecido, por um lado e, por outro, a imagem de um novo mundo por vir e a nova visão de mundo. É desse modo que o objeto poético cerca as imagens que são sem serem percebidas de um mundo, ele é o dispositivo que nos dá a vê-las, a partir de agora, como paisagens nascentes.

Finalizando, em toda fabulação cercamos o jardim paisagístico de um mundo. A cada fabulação criou-se um cartão-portal, como se este fosse inscrição poéticovisual a demarcar a paisagem. No cartão-portal, a imagem é estruturada como um limiar de passagem "para fazer sentir novamente o mesmo afeto que o desse puro sensível que talvez pense, mas que certamente não escreve." (apud RANCIÈRE, 2000, p. 514).

\section{Referências bibliográficas:}

BALTRUSAITIS, Jurgis. Aberrações. In: Jardins e terras de ilusão. Rio de Janeiro: Editora UFRJ, 1999.

BARTHES, Roland. A câmara clara. Rio de janeiro: Nova Fronteira, 1984.

DELEUZE, Gilles \& GUATTARI, Félix. A imagem-tempo. São Paulo: Brasiliense, 1990. O que é a filosofia? São Paulo: Editora 34, 1992.

. Mil Platôs. São Paulo: Editora 34, 1995-1997 [editado em 5 volumes].

DIDI-HUBERMAN, Georges. O que vemos, o que nos olha. São Paulo: Editora 34, 1998.

FOUCAULT, Michel. De outros espaços. Tradução de Pedro Moura. In: www. Virose.pt, com acesso em 02 de dezembro de 2008.

GIEDION, S. Espaço, tempo e arquitetura. O desenvolvimento de uma nova tradição. São Paulo: Martins Fontes, 2004.

MADERUELO, Javier. Del arte del paisaje al paisaje como arte. Revista del Occidente, Madrid, n. 189, p. 23-36, 1997.

PERNIOLA, Mario. Do sentir. Lisboa: Editorial Presença: 1993.

RANCIÈRE, Jacques. A partilha do sensível. Estética e política. São Paulo: Exo experimental org.; Ed. 34, 2005.

VITRUVIO. Tratado de arquitetura. São Paulo: Martins Editora, 2007. 